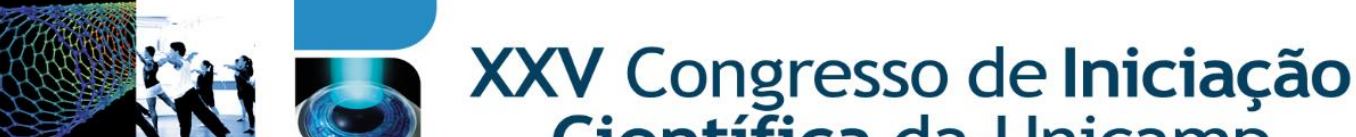 Científica da Unicamp
}

18 a 20 Outubro Campinas | Brasil

\section{O USO DO PHMB NO CONTROLE DO BIOFILME EM FERIDA CRÔNICA: REVISÃO INTEGRATIVA.}

\section{Jéssica da Silva Pereira*, Maria Helena de Melo Lima.}

\section{Resumo}

O objetivo desta revisão integrativa foi identificar e analisar as evidências disponíveis na literatura quanto a efetividade do PHMB no controle do biofilme. Este estudo incluiu 15 artigos que avaliaram sua eficácia também em conjunto à outros produtos e técnicas. Resultados indicam que o PHMB é um antisséptico de baixa toxicidade, contribuiu para redução da dor em pacientes com feridas crônicas e, mostrou efeito anti-biofilme contra os principais micro-organismos, como Staphylococcus aureus e Pseudomonas aeruginosa, embora não os tenha erradicado por completo.

\section{Palavras-chave:}

Ferida crônica, processo de cicatrização, Polihexametileno Biguanida (PHMB).

\section{Introdução}

A função primária da pele é a proteção ao meio externo e na presença de uma ferida inicia-se o reparo tecidual com objetivo de reestabelecer sua função. ${ }^{1}$ Em feridas crônicas o biofilme tem participação no atraso do reparo. ${ }^{2}$ O controle do biofilme pode ser feito com o uso do Polihexametileno biguanida (PHMB), um antisséptico composto de uma mistura sintética de polímeros com amplo espectro antimicrobiano, incluindo bactérias Gram-positivas e Gramnegativas, além de fungos e vírus. ${ }^{3,4} \mathrm{~A}$ prática baseada em evidências pode contribuir com conhecimento que fornece subsídios para que o profissional tome a decisão baseada em evidências científicas. Deste modo, o objetivo do presente estudo foi identificar e analisar as evidencias cientificas disponíveis na literatura quanto a efetividade do PHMB no controle do biofilme em feridas crônicas.

\section{Resultados e Discussão}

Trata-se de uma revisão integrativa (RI) com a seguinte pergunta norteadora: "Qual a efetividade do PHMB no tratamento de biofilme em feridas crônicas"? No Quadro 1 estão incluídos a seleção dos artigos do estudo.

\begin{tabular}{|c|c|c|c|c|}
\hline \multicolumn{5}{|c|}{$\begin{array}{l}\text { Estratégia de busca nas bases de dados MEDLINE, Web of Science, Scopus, Embase e BVS. } \\
\text { (Data limite: } 24 / 05 / 2017 \text { ) } \\
\text { Descritores: (wound) AND (biofilm) AND (PHMB OR Polyhexamethylene bigunide) }\end{array}$} \\
\hline $\begin{array}{c}\text { PubMed } \\
\mathrm{n}=19\end{array}$ & $\begin{array}{c}\text { Web of Science } \\
n=11\end{array}$ & $\begin{array}{c}\text { Scopus } \\
\mathrm{n}=11\end{array}$ & $\begin{array}{c}\text { Embase } \\
\mathrm{n}=12\end{array}$ & $\begin{array}{l}\text { BVS } \\
n=0\end{array}$ \\
\hline \multicolumn{5}{|c|}{ Exclusão de artigos repetidos } \\
\hline $\begin{array}{c}\text { PubMed } \\
\mathrm{n}=19\end{array}$ & $\begin{array}{c}\text { Web of Science } \\
n=10\end{array}$ & $\begin{array}{c}\text { Scopus } \\
\mathrm{n}=11\end{array}$ & $\begin{array}{c}\text { Embase } \\
\mathrm{n}=12\end{array}$ & $\begin{array}{l}\mathrm{BVS} \\
\mathrm{n}=0\end{array}$ \\
\hline \multicolumn{5}{|c|}{ Exclusão depois da leitura do resumo e/ou texto completo } \\
\hline $\begin{array}{c}\text { PubMed } \\
n=14\end{array}$ & $\begin{array}{c}\text { Web of Science } \\
n=1\end{array}$ & $\begin{array}{c}\begin{array}{c}\text { Scopus } \\
n=0\end{array} \\
\text { n }\end{array}$ & $\begin{array}{c}\text { Embase } \\
n=0\end{array}$ & $\begin{array}{l}\text { BVS } \\
n=0\end{array}$ \\
\hline
\end{tabular}

Quadro 1. Artigos incluídos na RI.

O quadro 2 apresenta os 15 artigos encontrados e os principais resultados.

\begin{tabular}{|c|c|}
\hline $\begin{array}{c}\text { Autores/Ano/ } \\
\text { País/Procedência }\end{array}$ & Principais resultados \\
\hline $\begin{array}{l}\text { Davis et al }{ }^{(19) /} / \\
\text { 2017/EUA/ } \\
\text { PubMed }\end{array}$ & $\begin{array}{l}\text { PHMB foi o mais eficiente na redução de Staphylococcus Aureus } \\
\text { Resistente à Meticilina (MRSA). }\end{array}$ \\
\hline $\begin{array}{l}\text { Crone et al } \mathrm{al}^{(20)} \\
\text { 2015/Dinamarca } \\
\text { PubMed }\end{array}$ & $\begin{array}{l}\text { UAW e exposição a } 24 \text { h de PHMB mostrou redução significativa } \\
\text { (p<0.05), porém não uma erradicação completa, de CFU de S. } \\
\text { aureus em dois meios de cultura. }\end{array}$ \\
\hline $\begin{array}{c}\text { Durante et } \\
\mathrm{al}^{(21) / 2014 / / \mathrm{lá} l i a /} \\
\text { PubMed }\end{array}$ & $\begin{array}{l}\text { A média da escala de dor diminuiu }(p<0,00005) \text {, houve redução do } \\
\text { biofilme (de } 23,4 \% \text { das feridas para } 1,6 \%) \text { e a frequência de troca de } \\
\text { curativo foi reduzida. }\end{array}$ \\
\hline $\begin{array}{l}\text { Incani et al }{ }^{(22)} \\
2014 / \text { Canadá. } \\
\text { PubMed }\end{array}$ & $\begin{array}{l}\text { Apenas } \mathrm{Ag}_{5} \mathrm{IO}_{6} \text { se manteve eficaz contra micro-organismos, PHMB } \\
\text { alcançou } 28 \text { dias de eficácia apenas contra } C \text {. albicans. }\end{array}$ \\
\hline $\begin{array}{l}\text { Phillips et al }{ }^{(23)} \\
\text { 2013/ EUA. } \\
\text { PubMed }\end{array}$ & $\begin{array}{l}\text { Após 24h de NPWTi com solução salina e agentes antimicrobianos } \\
\text { tecido ficou limpo de bactéria por exame visual, embora altos níveis } \\
\text { de biofilme e bactérias planctônicas foram visualizados por técnica de } \\
\text { cultura. }\end{array}$ \\
\hline $\begin{array}{l}\text { Phillips et al }{ }^{(24)} \\
\text { 2013/USA. } \\
\text { PubMed }\end{array}$ & $\begin{array}{l}\text { Não houve diferença significativa na redução do Bioburden depois } \\
\text { de } 0.1 \% \text { de PHMB gel e } 0.2 \% \text { em gaze. }\end{array}$ \\
\hline
\end{tabular}

\begin{tabular}{|c|c|}
\hline 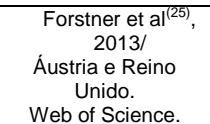 & $\begin{array}{l}\text { A associação de metacrilato com } 0.02 \% \text { PHMB reduziu de } \log _{10} 7.00 \\
\text { cfu/g para } \log _{10} 4.00 \mathrm{cfu} / \mathrm{g} \text { depois de } 120 \mathrm{~h} \text {. Com } 0.4 \% \text { PHMB reduziu } \\
\text { para } \log _{10} 3.79 \mathrm{cfu} / \mathrm{g} \text { no mesmo período e a junção de } 0.1 \% \text { PHMB } \\
\text { com } 0.1 \% \text { + Betaína inibiu o crescimento apenas nas primeiras } 48 \mathrm{~h} \text {. }\end{array}$ \\
\hline $\begin{array}{l}\text { Wild et al }{ }^{(15)} \\
\text { 2012/Áustria } \\
\text { PubMed }\end{array}$ & $\begin{array}{l}\text { Após duas semanas de tratamento, } 100 \% \text { dos pacientes }(\mathrm{p}<0.05) \\
\text { tratados com hydrobalance dressing+PHMB tiveram MRSA } \\
\text { erradicados das úlceras, com aumento de tecido de granulação e } \\
\text { redução da dor da ferida. }\end{array}$ \\
\hline $\begin{array}{l}\text { Eberlein et al }{ }^{(26)} \\
\text { 2012/Áustria e Suíça } \\
\text { PubMed }\end{array}$ & $\begin{array}{l}\text { Houve uma melhora na escala de dor antes da troca do curativo } \\
\text { mais significativa no grupo tratado com PHMB }(p=0.03) \text {, que } \\
\text { mostrou maior redução do Bioburden }(p<0.0009) \text {. }\end{array}$ \\
\hline $\begin{array}{l}\text { Lenselink et al }{ }^{(27)} \\
\text { 2011/Holanda. } \\
\text { PubMed. }\end{array}$ & $\begin{array}{l}63 \% \text { dos pacientes tiveram uma boa redução do biofilme, } 32 \% \\
\text { tiveram moderada e } 6 \% \text { não teve redução. Todos os pacientes } \\
\text { tiveram aumento significativo do tecido de granulação }(p<0.04) \text {, além } \\
\text { de referirem redução da dor. }\end{array}$ \\
\hline $\begin{array}{l}\text { Hübner et al }\left.\right|^{(28)} \\
\text { 2010/Alemanha. } \\
\text { PubMed. }\end{array}$ & $\begin{array}{l}\text { No teste com objetos de silicone, apenas } 0.04 \% \text { PHMB teve redução } \\
\text { significativa da atividade metabólica dos micro-organismos } \\
\text { comparada ao grupo controle. }\end{array}$ \\
\hline $\begin{array}{l}\text { Lipp et al }{ }^{(29)} \\
\text { 2010/EUA. } \\
\text { PubMed. }\end{array}$ & $\begin{array}{l}\text { O crescimento bacteriano no grupo tratado com PHMB } 0,2 \% \text { foi } \\
\text { estatisticamente menor que as coberturas sem propriedades } \\
\text { antimicrobianas ( } \leq \leq 0.01) \text {, exceto para o tratamento com } 100 \% \\
\text { algodão }(p=0.07) \text {. }\end{array}$ \\
\hline $\begin{array}{l}\text { Romanelli et al }\left.\right|^{(30)} \text {, } \\
\text { 2010/lália } \\
\text { PubMed }\end{array}$ & $\begin{array}{l}\text { Depois de } 4 \text { semanas de tratamento o } \mathrm{pH} \text { na superfície da ferida foi } \\
\text { de } 8.9 \text { para } 7.0 \text {, sendo significativamente menor que no grupo } \\
\text { controle }(p<0.05) \text {, mostrando, um melhor controle do bioburden. } \\
\text { controle da dor durante e no final do tratamento foi melhor no grupo } \\
\text { tratado se comparado ao controle }(\mathrm{p}<0.05) \text {. }\end{array}$ \\
\hline $\begin{array}{l}\text { Kirker et al }^{(16)} \text {, } \\
\text { 2009/EUA. } \\
\text { PubMed. }\end{array}$ & $\begin{array}{l}72 \text { e } 168 \text { h depois do tratamento, não foram encontradas bactérias. } \\
\text { O PHMB foi capaz além de reduzir o crescimento bacteriano e o } \\
\text { Bioburden, melhorar a cicatrização. }\end{array}$ \\
\hline $\begin{array}{l}\text { Horrocks } A^{(31)} / \text { Reino } \\
\text { Unido/2006/ } \\
\text { PubMed }\end{array}$ & $\begin{array}{l}\text { Biofilme foi eliminado mostrando redução significativa dos níveis de } \\
\text { exsudato; pacientes relataram melhora na qualidade de vida e } \\
\text { houve um relato de redução considerável da dor. }\end{array}$ \\
\hline
\end{tabular}

Quadro 2. Descrição dos artigos incluídos.

\section{Conclusões}

Resultados indicam que o PHMB é um antisséptico com baixa toxicidade e contribui para redução da dor em pacientes com feridas crônicas e, embora não seja efetivo na erradicação total, foi eficaz contra os principais microorganismos formadores de biofilme, como Staphylococcus aureus e Pseudomas aeruginosa.

\section{Agradecimentos}

Agradecimento ao Serviço de Apoio ao Estudante (SAE) e ao Conselho Nacional de Desenvolvimento Científico e Tecnológico (CNPq).

${ }^{1}$ Demidova-Rice TN, Hamblin MR, Herman IM. Acute and impaired wound healing: pathophysiology and current methods for drug delivery, part 1: normal and chronic wounds: biology, causes, and approaches to care. Adv Skin Wound Care. 2012;25(7):304-14.

${ }^{2}$ Harmsen M, Yang L, Pamp SJ, Tolker-Nielsen T. An update on Pseudomonas aeruginosa biofilm formation, tolerance, and dispersal. FEMS Immunol Med Microbiol. 2010;59(3):253-68.

Butcher M. PHMB: an effective antimicrobial in wound bioburden management. British Journal of Nursing. 2012;21(12):16-21.

${ }^{4}$ Hubner NO, Kramer A. Review on the efficacy, safety and clinical applications of polihexanide, a modern wound antiseptic. Skin Pharmacology and physiology. 2010;23(1):17-27. 